\title{
Acute Phase Reactants and Complement Components as Indicators of Recurrence in Human Cervical Cancer*
}

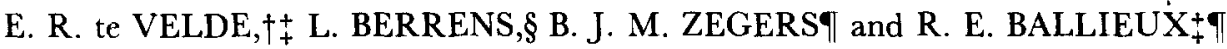

Departments of $\dagger$ Obstetrics and Gynaecology, ${ }_{+}^{+C l i n i c a l}$ Immunology and $\$$ Experimental Allergy of the University Hospital and the $\lceil$ department of Immunology, University Children Hospital "Het Wilhelmina Kinderziekenhuis", Utrecht, the

Netherlands

\begin{abstract}
Twenty patients with invasive cervical cancer of the squamous cell type were treated by radiotherapy and/or radical hysterectomy. During a follow-up period of approximately 2 yr in 10 of these patients a recurrence was established. Serial determinations of three acute phase reactants $\left(\alpha_{1}\right.$-acid glycoprotein, haptoglobin and $C$-reactive protein) and of three complement components $(C 4, C 3$-proactivator and $C 9)$ were performed before and after therapy and either at the time of recurrence (recurrence group), or at the end of the follow-up period (non-recurrence group). Sequential analysis of the serum levels of all the parameters tested showed a significant increase at the time of recurrence. The most conclusive results were obtained with haptoglobin and the C9-component of complement.
\end{abstract}

\section{INTRODUCTION}

EARLY diagnosis of cancer recurrence is a prerequisite for the successful treatment of the patient. Since the conventional clinical methods only allow for the detection of recurrence at a rather late stage, a large number of studies have been undertaken to examine biochemical parameters for their potential to reflect tumour mass. Attention has been focussed on the detection of unique tumour products, which might meet the criteria of specificity and sensitivity. At present only human chorionic gonadotrophin in choriocarcinoma, alpha-foetoprotein in malignant hepatoma and some teratoma and carcinoembryonic antigen in colorectal cancer fulfill these requirements to some extent $[1,2]$.

It is conceivable, however, that physiological body fluid proteins in cancer patients may vary from normal values to such a degree, that they might serve as indicators of tumour

Accepted 7 December 1978.

*This investigation was supported by a grant from the Netherlands Cancer Society (Koningin Wilhelmina Fonds, KWF). Projectnumber: U.K.C. gyn. 76-2.

Correspondence to: E. R. te Velde, M.D., Dept. of Obstetrics and Gynaecology, University Hospital, Catharijnesingel 101, Utrecht, the Netherlands. mass. In this respect, acute phase reactants (APR) and complement components (CiCi) have been investigated in several human malignancies and it has been demonstrated that abnormalities in the serum levels of these factors are frequently found [3-11]. Studies in patients with cervical cancer have until now been limited to protein analysis of a single APR, i.e. $\alpha_{1}$-antitrypsin [12].

Most of the investigations on changes in serum levels of APR and CC have been designed in a transversal fashion, comparing patients with different stages of cancer with healthy individuals. In case the results suggested a progressive change in the mean values of the investigated parameters towards the advanced stages relative to the control group, the conclusion was often put forward that abnormal serum levels concur with a bad prognosis, recurrence or hidden metastases. However, quantitative changes in APR and CG cannot be expected exclusively to reflect malignant growth, because abnormal levels of APR are also observed in response to injury, infection and some chronic diseases. Furthermore, the complement system is a defense mechanism triggered by many agents. Considerable individual variations of APR and CCproteins due to differences in phenotypes, 
production rates, catabolism, age and/or sex are known to exist. It therefore seems unlikely that a single determination of $\mathrm{APR}$ or $\mathrm{CC}$ will allow the detection of tumour recurrence in individual patients. However, changes in serum levels which follow a distinct pattern as detected by serial measurements in a single patient might reflect tumour growth. This approach was recently advocated in the literature and promising results in some patients with colorectal cancer $[13,14]$, breast cancer [15] and neuroblastoma [16] have been claimed. In the present investigation three APR $\left(\alpha_{1}\right.$-acid glycoprotein, haptoglobin and $\mathrm{C}$-reactive protein) and three CG (C4, C3-proactivator, and C9) have been determined in a longitudinal fashion in 20 patients with invasive cervical carcinoma. The aim of the study was to establish whether or not, (a) pre- or posttreatment serum levels are of prognostic significance and (b), values obtained by limited serial determinations will allow for detection of tumour recurrence in individual patients.

\section{MATERIALS AND METHODS}

\section{(a) Patients}

Twenty patients with invasive cervical carcinoma were investigated. Of these, $10 \mathrm{de}$ veloped a recurrence while the remaining 10 patients were found to be tumour-free at the end of the follow-up period of about $2 \mathrm{yr}$. These patients were the first recurrence and non-recurrence cases in a group of $100 \mathrm{pa}$ tients included in a research program on potential prognostic and monitory markers in invasive cervical cancer. All tumours were classified histologically as squamous cell carcinomas varying from a non-differentiated to a well-differentiated type. Stages were defined according to the FIGO principles [17]. Data on therapy and recurrence are shown in Table 1. One patient had a heart attack during the follow-up period for which a pacemaker had to be inserted. She is considered tumour-free up till now. One patient died as a consequence of radiation therapy (bilateral ureteral obstruction). At autopsy both parametria were completely fibrotic, but no cancer tissue was detected. Serum levels of the investigated parameters were normal threc months prior to death. One patient was suffering from hypertension for which she was treated with furosemide and $\alpha$-methyldopa. In the course of the follow-up period she started to suffer from severe recurrent cystitis; no cancer recurrence occurred in this patient. The remaining patients were not suffering from major disease during the follow-up period, other than cervical carcinoma.

\section{(b) Serum proteins}

$\alpha_{1}$-Acid glycoprotein $\left(\alpha_{1}\right.$-AGP), haptoglobin (Hp), C-reactive protein (CRP), C3 pro-activator (C3PA) and $\mathrm{C} 4$ were determined by single radial immunodiffusion. Antisera, standards and immunodiffusion plates were obtained from Behringwerke. C-reactive protein was quantitatively determined only in sera that were positive in the latex agglutination test (Behringwerke). The lower level of detection of this test is approximately $1 \mathrm{mg} / 100 \mathrm{ml}$. The serum levels of each protein were determined in duplicate and were expressed in $\mathrm{mg} / 100 \mathrm{ml}$. Rocketelectrophoresis was performed to determine C9 levels. Since no standard protein was available, a reference serum composed of the pooled sera of four healthy individuals, was run as internal standard; C9 values were expressed in per cent of this normal pool.

\section{(c) Blood sampling}

The first blood sample of each patient was taken 6 days before starting therapy (T1). During treatment, and immediately thereafter a considerable increase in serum levels of the different parameters was observed, caused by tissue destruction and infections associated with operation and radiotherapy. In most cases this elevation leveled off after a few weeks. The second sample (T2) was taken at the time the serum levels of the particular

Table I. Distribution of stage, recurrence and therapy modality in 20 patients with invasive cervical carcinoma

\begin{tabular}{lccc}
\hline Stage (FIGO) & I & II & III \\
\hline Number of patients & 6 & 6 & 8 \\
Recurrence & 0 & 5 & 5 \\
Radiotherapy only & 1 & 5 & 8 \\
Radical hysterectomy + lymphadencctom! & 5 & 1 & 0 \\
Megavolt therapy after operation & I & 1 & \\
\hline
\end{tabular}


ARP and CC had stabilized. On the average, this was about 13 weeks after the first sample, both in the recurrence and the non-recurrence group (range 6-21). The third sample (T3) was the final bleeding in each patient. In the recurrence group this was the sample taken at the time recurrence was clinically established (5 patients). In 4 patients, the final sample was taken $8,5,6$ and 26 weeks before and in one patient 6 weeks after recurrence was ascertained. The mean point of time of the final bleeding in the recurrence group was 43 weeks (range 15-89) and in the nonrecurrence group 108 weeks (range 73-146) after the first sample.

The sera were divided into $0.6 \mathrm{ml}$ samples and stored at $-20^{\circ} \mathrm{C}$. Each aliquot was thawed only once for use in this study. Analyses of the samples of a single patient at $\mathrm{T} 1, \mathrm{~T} 2$ and T3 were carried out simultaneously.

\section{(d) Statistical methods}

The one-sided Wilcoxons two rank sum test was applied, unless otherwise stated.

\section{RESULTS}

The median serum values of the investigated parameters at the three different points in time and the corresponding ranges are given in Table 2. In Figs. 1-3 serum values for each parameter in every patient at $\mathrm{T} 1, \mathrm{~T} 2$ and 'T3 are presented. For clarity's sake, the time gap between $\mathrm{T} 1$ and $\mathrm{T} 2$, or $\mathrm{T} 3$ respectively, has been averaged as described in Materials and Methods.

The difference between the pretreatment values of the recurrence and non-recurrence groups was statistically significant $(P<0.05)$ for $\mathrm{Hp}, \mathrm{C} 4$ and $\mathrm{C} 9$, but not for $\alpha_{1}-\mathrm{AGP}$ and C3PA. Grouping of pretreatment levels in relation to tumour stage revealed a significant difference for $\mathrm{Hp}, \mathrm{C4}, \mathrm{C} 3 \mathrm{PA}$ and C9 (Kruskal-Wallis test, $P<0.05$ ). No differences for these various parameters were found between stages II and III. Combining stages II and III and comparing these with stage I significant differences were detected for all parameters investigated $(P<0.01)$. If clinical recurrence is considered as an outgrowth of tumour cell clusters not eliminated by therapy, an increment in the serum levels of the investigated parameters in the recurrence group after therapy would be conceivable. However, no significant differences between the recurrence and non-recurrence group were found at T2. At T3 statistically significant differences between the recurrence and nonrecurrence group were found for all the investigated parameters with the exception of C4 $(P<0.01)$.

The longitudinal nature of this study permits a different sort of analysis. The increase

Table 2. Median serum levels (ranges in parentheses) of the investigated proteins in 20 patients with invasive cervical cancer

\begin{tabular}{lccc}
\hline $\begin{array}{l}\text { Investigated } \\
\text { Proteins }\end{array}$ & $\mathrm{T} 1$ & $\begin{array}{c}\mathrm{T} 2 \\
\text { Non-recurrence }\end{array}$ & $\mathrm{T} 3$ \\
\hline$\alpha_{1}$-APG & $93(40-166)$ & $82(52-138)$ & $80(40-117)$ \\
Hp & $238(82-502)$ & $232(134-330)$ & $220(96-322)$ \\
CRP & $<1(<1-2)$ & $<1(<1-<1)$ & $<1(<1-1.9)$ \\
C4 & $35.2(14.8-45.6)$ & $33(21.6-44.8)$ & $39.8(20.8-46.8)$ \\
C3PA & $22.4(7.8-30.2)$ & $22.4(10.0-27.6)$ & $21.5(16.0-27.2)$ \\
C9 & $126(89-212)$ & $145(105-203)$ & $125(73-178)$ \\
& & & \\
& & Recurrence & \\
$\alpha_{1}$-APG & $104(61-183)$ & $89(67-166)$ & $162(78-300)$ \\
Hp & $345(176-598)$ & $234(47-638)$ & $508(282-678)$ \\
CRP & $<1(<1-2.1)$ & $<1(<1-3.1)$ & $2.4(<1-25.6)$ \\
C4 & $44.6(32.4-80.8)$ & $36.2(19.4-60.4)$ & $45.9(24.2-71.6)$ \\
C3PA & $26.2(16.6-41.6)$ & $25.5(15.2-36.2)$ & $34.3(25.8-44)$ \\
C9 & $169(128-262)$ & $157(86-264)$ & $226(143-294)$ \\
\hline
\end{tabular}

$\alpha_{1}-\mathrm{APG}=\alpha_{1}$-acid glycoprotein, $\mathrm{Hp}=$ haptoglobin, $\mathrm{CRP}=\mathrm{C}$-reactive protein, C3PA $=\mathrm{C} 3$-proactivator, $\mathrm{T} 1=$ before therapy, $\mathrm{T} 2=$ after therapy, $\mathrm{T} 3=$ time of the final bleeding. C9, determined by rocketelectrophoresis is expressed in per cent of normal. 'The other proteins have been determined by single radial immunodiffusion and are expressed in $\mathrm{mg} / 100 \mathrm{ml}$. 


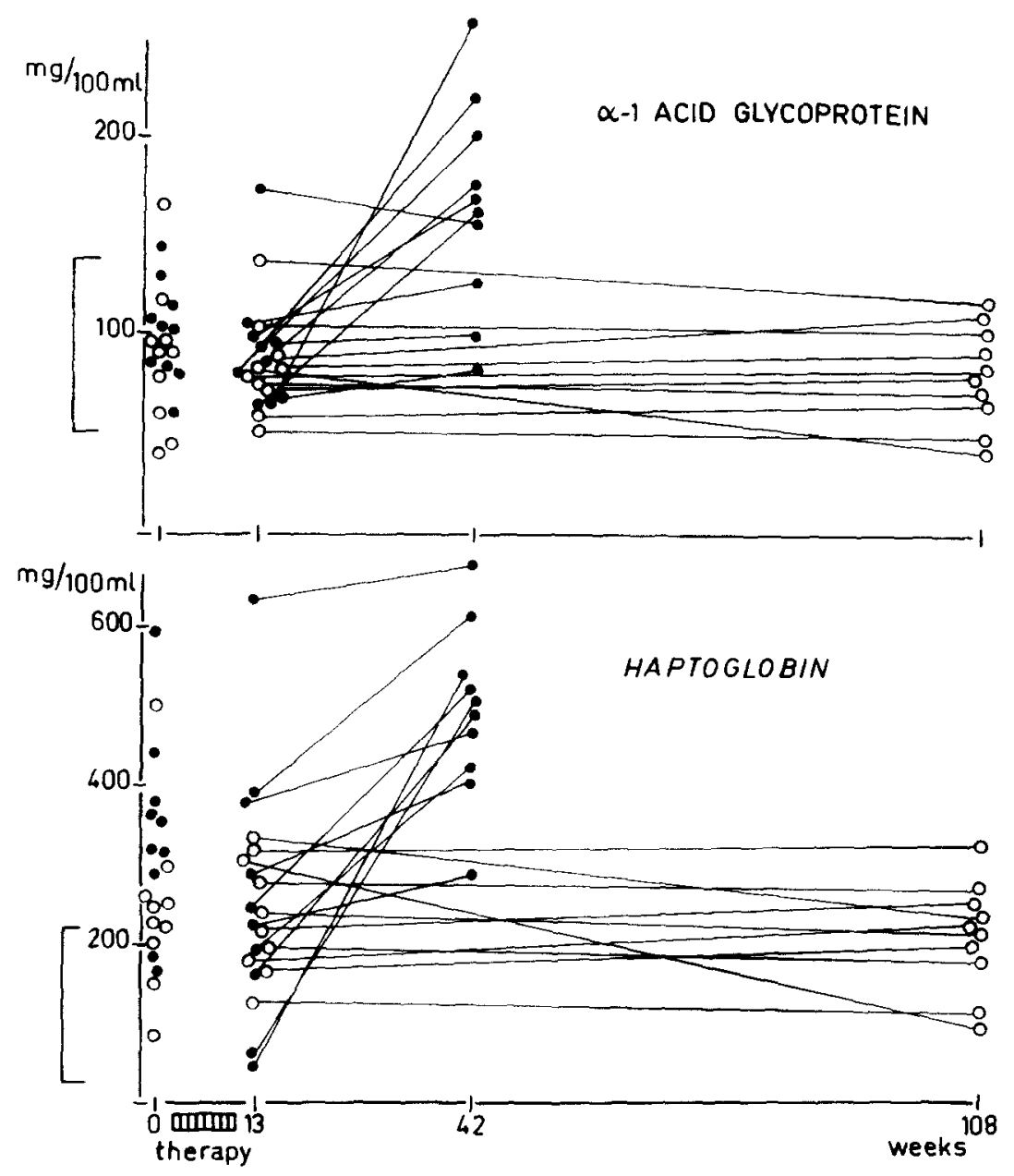

Fig. 1. $\alpha_{1}$-Acidglycoprotein and haptoglobin serum levels in 20 patientswith invasive cervical carcinoma, before and after therapy, al the time of recurrence and at the end of the follow-up period. - = patients with a recurrence; $\mathrm{O}-\mathrm{O}=$ patients without a recurrence; $[=$ normal range.

of any given parameter in the final two samples of a single patient can be expressed as:

$$
\mathrm{T} 3-\mathrm{T} 2 \text { (serum value) } / \mathrm{T} 3-\mathrm{T} 2 \text { (weeks). }
$$

This value has not been computed for the complement components in one recurrence patient, because for the analysis of these proteins no sample was available at T3. 'The differences in longitudinal increase between the recurrence and non-recurrence groups were statistically significant for all the parameters tested $(P<0.01)$. For $\mathrm{Hp}$ and $\mathrm{C9}$, no overlap between the values of the recurrence and non-recurrence group was observed.

Because most serum levels remained below the level of detection with the latex agglutination test, C-reactive protein values have not been included in the statistical analyses. From Fig. 3 it may be concluded that an increase of
CRP to over $1 \mathrm{mg} / 100 \mathrm{ml}$ raises suspicion of recurrence, provided the patient does not suffer from some other disease. The one nonrecurrence case with a detectable CRP level $(1.9 \mathrm{mg} / 100 \mathrm{ml})$ at $\mathrm{T} 3$ was a patient with severe recurrent cystitis (see Materials and Methods).

\section{DISCUSSION}

In the present study statistical evaluation of pretreatment levels of $\mathrm{Hp}, \mathrm{C} 4$ and C9 were correlated with the prognosis. On further consideration, it was concluded that the differences in the serum levels of these three proteins at $\mathrm{T} 1$ merely reflected differences in tumour stage. Therefore, the pretreatment levels of the investigated proteins are not of more prognostic value to the individual patient with invasive cervical carcinoma than the clinical assessment of tumour stage. 

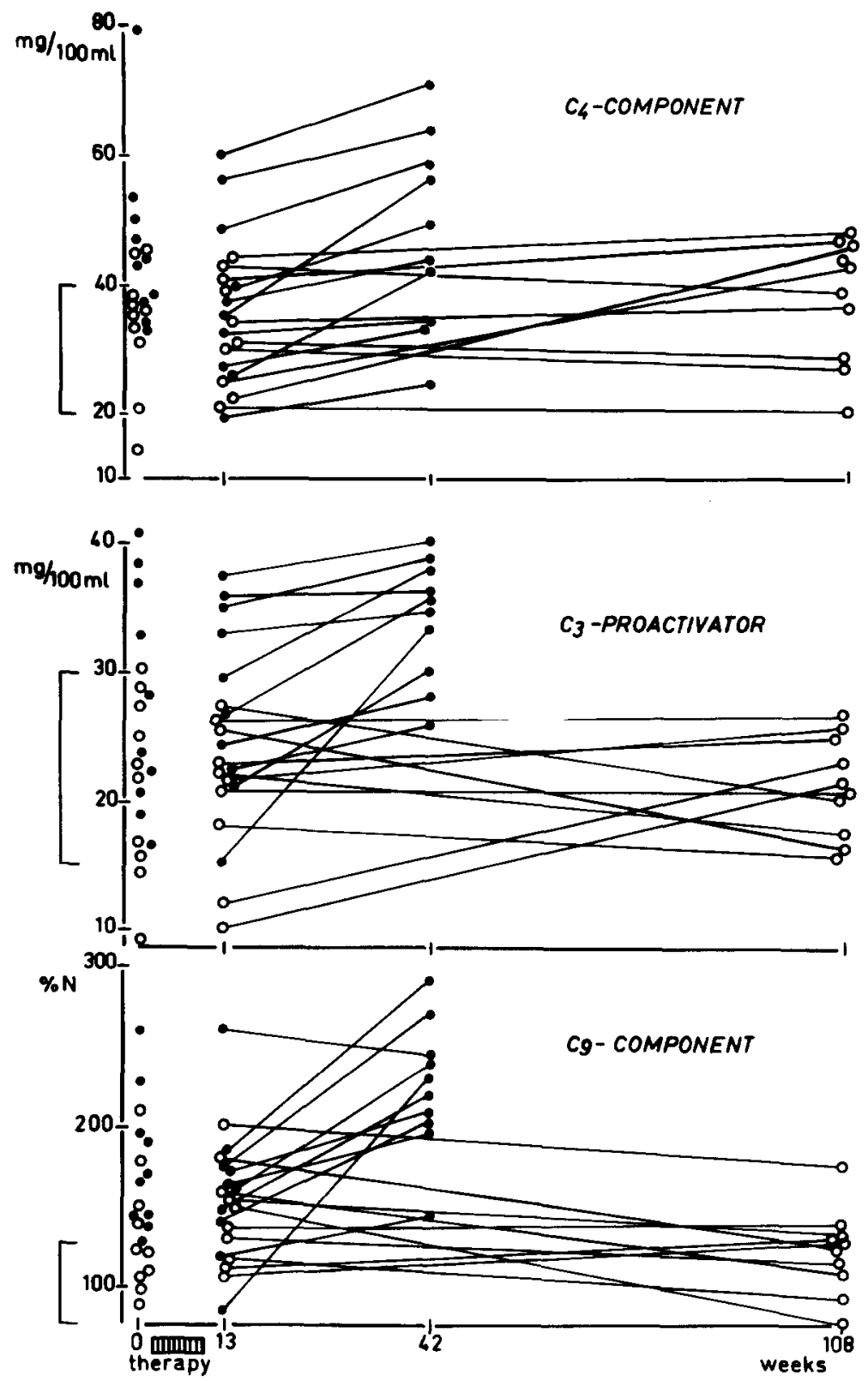

Fig. 2. C4, C3-proactivator and C9 serum levels in 20 patients with invasive cervical carcinoma, before and after therapy, at the time of recurrence and at the end of the follow-up period. $-\mathrm{O}=$ patients with a recurrence; $\mathrm{O}-\mathrm{O}=$ patients without a recurrence; $[=$ normal range.

A significant difference in the serum levels of the investigated proteins (except C4) could, however, be demonstrated between the recurrence and non-recurrence group at T3. Sequential studies in single patients yielded variations in time which seem more indicative of recurrence for the individual patient. Longitudinal increases of all the investigated parameters were suggestive of tumour mass at the time of clinical recurrence (in 4 patients even 8-26 weeks prior to recurrence). Most conclusive in this respect were $\mathrm{Hp}$ and $\mathrm{C} 9$, because no overlap between recurrence and non-recurrence values was observed. It is note- worthy that the serum levels of the CC, seem to follow the same pattern as those of APR. Indeed, it has been described in some other diseases that several individual $\mathrm{CC}$ respond as APR [18-20].

As increased APR and GC levels not only reflect tumour growth but also tissue destruction and infectious processes, associated with operation trauma and radiotherapy, monitoring can only be undertaken several weeks after therapy. Moreover, if a patient contracts a disease during the follow-up period, which in itself may cause elevated serum levels of APR and CC, no conclusions with regard to 


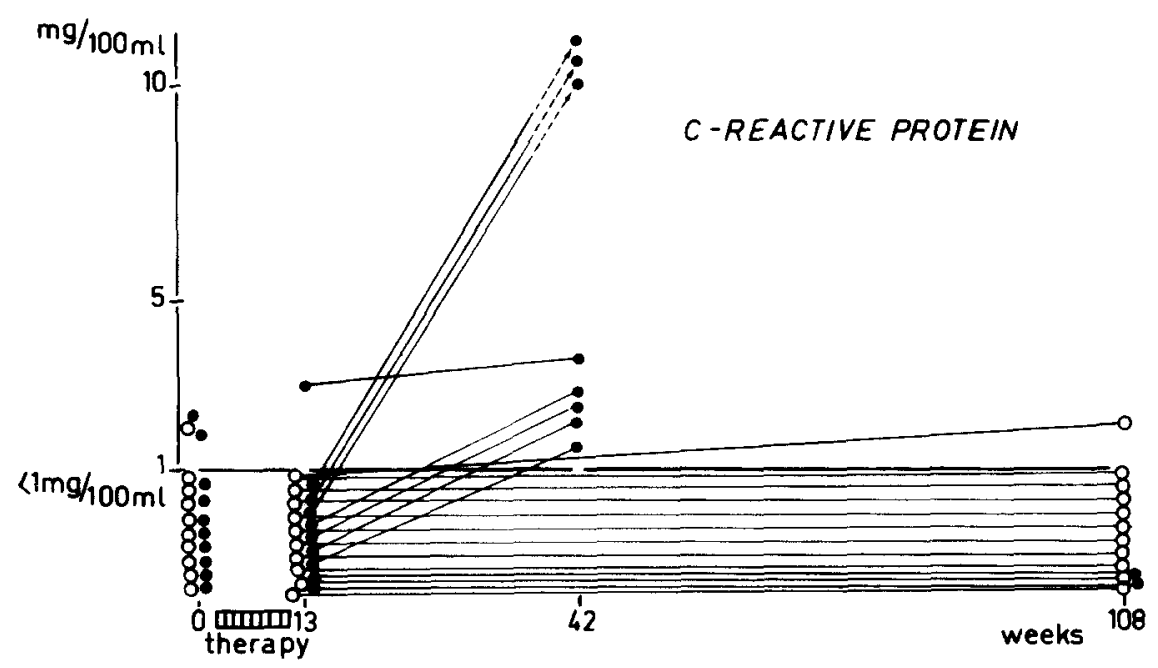

lig. 3. C-reactive protein serum levels in 20 patients with invasive cervical carcinoma, before and after therapy, at the time of recurrence and at the end of the follow-up period. - $=$ patients with a recurrence; $\bigcirc-O=$ patients acithout a recurrence; $1 \mathrm{mg} / 100 \mathrm{ml}=$ lower level of detection.

tumour recurrence should be drawn. It is our experience, however, that such conditions will be recognized by the clinician and subsequently will not lead to "false positive" interpretations. In spite of these obvious drawbacks due to non-specificity, the data obtained indicate that on the basis of sequential determination of $\mathrm{APR}$ and $\mathrm{CC}$, with emphasis on $\mathrm{Hp}$ and $\mathrm{C9}$, tumour growth can potentially be monitored. If it can be established that the serum levels of these protcins start 10 increase at an early stage of recurrence, these lindings may have important clinical value. Studics are in progress to determine whether sequential measurement of APR and $C C$ at 3 or 4 months intervals will actually lead to an early detection of tumour recurrence.

\begin{abstract}
Acknowledgements---The authors are indebted to $\mathrm{Dr}$. Ir. J. Faber (Institute of mathematical statistics. University of Utrecht) for statistical evaluation of the results and to Prof. dr. H. A. van Peperzecl and Dr. J W. Barents (Dept. of Radiotherapy respectively Gynaecology, University Hospital Utrech1) for continued interest and critical remarks. They would also like to acknowledge the valuable help of Mrs. A. Graafmans in collecting the bloodsamples and administrating the clinical data.
\end{abstract}

\section{REFERENCES}

1. J. I. Lewis, Chemotherapy of gestational choriocarcinoma. Cancer (Philad.) 30, $1517(1972)$.

2. R. B. Herbermax, Immunologic approaches to the diagnosis of cancer. Cancer (Philad.) 37, 549 (1976).

3. W. K. Mueller, R. Handschemacher and M. E. Wade, Serum haptoglobin in patients with ovarian malignancies. Obstet. Gynec. 38, 427 (1971).

4. C. C. Harris, M. H. Cohen, R. Connor, A. Primack, G. Saccomanno and R. C. Talamo, Serum alpha ${ }_{1}$-antitrypsin in patients with lung cancer or abnormal sputum cytology. Cancer (Philad.) 38, 1655 (1976).

5. R. C. Coombs, J. C. Gaze't, J. P. Sloone, T. J. Powles, H. T. Ford, D. J. R. Laurence and A. M. Neville, Biochemical markers in human breast cancer. Lancet i, 132 (1977).

6. W. P. Bradley, A. P. Blasco, J. F. Weiss, J. C. Alexander, N. A. Silverman and P. B. Chretien, Correlation among serum protein-bound carbohydrates, serum glycoproteins, lymphocyte reactivity, and tumor burden in cancer patients. Cancer (Philad.) 40, 2264 (1977).

7. B. Delpech. R. Laumoner, C. Martix and C. Ropartz, Augmentation de la $\beta$ lc globuline (C'3) chez les cancércux. Nour. Presse med. 4, 1045 (1975).

8. N. Bach-Mortensix, K. Osther and I. Sirgyer, Cl-esterase inactivators and $C 4$ in malignant disease. Lancel $\mathbf{i}, 1236$ (1975). 
9. H. Verhaegen, W. de Cock, J. de Gree and F. Verbruggen, Increase of serum complement levels in cancer patients with progressing tumors. Cancer (Philad.) 38, 1608 (1976).

10. J. L. Lichtenfeld, P. H. Wiernik, M. R. Mardiney and R. M. Zarco, Abnormalities of complement and its components in patients with acute leukemia, Hodgkin's disease and sarcoma. Cancer Res. 36, 3678 (1976).

11. A. J. Edwards, M. Lee and G. Harcourt, Serum immunoglobulins and C3 complement concentrations in malignancy. Clin. Oncol. 3, 65 (1977).

12. A. L. Latner, G. A. Turner and M. M. Lamin, Plasma alpha-1-anti-trypsin levels in early and late carcinoma of the cervix, Oncology 33, 12 (1976).

13. E. H. Cooper, R. Turner, A. Geekie, A. Munro Neville, J. C. Goligher, N. G. Graham, G. R. Giles, R. Hall and W. A. F. Macadam, Alphaglobulins in the surveillance of colorectal cancer. Biomedicine 24, 171 (1976).

14. A. Milford Ward, E. H. Cooper, R. Turner, J. A. Anderson and A. M. Neville, Acute phase reactant protein profiles: an aid to monitoring large bowel cancer by cea and serum enzymes. Brit. F. Cancer 35, 170 (1977).

15. J. G. Roberts, J. W. Keyser and M. Baum, Serum $\alpha_{1}$-acid glycoprotein as an index of dissemination in breast cancer. Brit. f. Surg. 62, 816 (1975).

16. J. Gerson, A. E. Evans and F. S. Rosen, The prognostic value of acute phase reactants in patients with neutoblastoma. Cancer (Philad.) 40, 1655 (1977).

16. J. Gerson, A. E. Evans and F. S. Rosen, The prognostic value of acute phase reactants in patients with neuroblastoma. Cancer (Philad.) 40, 1655 (1977).

17. H. L. Kottmeier, Presentation of therapeutic results in carcinoma of the female pelvis: experience of the annual report on the results of treatment in carcinoma of the uterus, vagina and ovary. Gynec. Oncol. 4, 13 (1976).

18. M. Schutte, R. Dicamelli, P. Murphy, M. Sadove and H. Gewurz, C3 proactivator (C3PA) as an acute phase reactant. Clin. exp. Immunol. 18, 251 (1974).

19. M. Schutte, R. Dicamelli, P. Murphy, M. Sadove and H. Gewurz, Effects of anesthesia, surgery and inflammation upon host defense mechanisms. I. Effects upon the complement system. Int. Arch. Allergy 48, 706 (1975).

20. L. Berrens, E. Jankowski and I. Jankowski-Berntsen, Complement component profiles in urticaria, dermatitis herpetiformis, and alopecia areata. Brit. 7. Dermatol. 95, 145 (1976). 